Check for updates

Cite this: RSC Adv., 2019, 9, 11484

Received 1st January 2019

Accepted 26th March 2019

DOI: 10.1039/c9ra00007k

rsc.li/rsc-advances

\section{Comparative study on gas sensing by a Schottky diode electrode prepared with graphene- semiconductor-polymer nanocomposites}

\begin{abstract}
Md Rokon Ud Dowla Biswas and Won-Chun On (D) *
This paper studies the performance of a gas sensor based on an organic/inorganic diode for ammonia $\left(\mathrm{NH}_{3}\right)$, nitrogen $\left(\mathrm{N}_{2}\right)$ \& oxygen $\left(\mathrm{O}_{2}\right)$ sensing under atmospheric conditions at room temperature and different humidity levels. The diode structure consists of a layer of different kinds of polymer (PTFE, PVDF, PANI) deposited on top of $\mathrm{BiVO}_{4}$. The polymer layer, which is filled with different ratios of graphene oxide (GO), is prepared from the solution phase. We show that the current-voltage $(I-V)$ response of the diode and the sensing performance are improved significantly by adding GO to the polymer layer. The sensing response is highest for a diode with $0.04 \mathrm{wt} \%$ of GO. At room temperature, the poly-GO (0.04 wt\%)/BiVO 4 Schottky diode shows a sensitivity of $194 \mathrm{ppm}$ upon exposure to $20 \mathrm{ppm}$ of $\mathrm{NH}_{3}$ in ambient air with rapid response and recovery times between 95 and $101 \mathrm{~s}$, respectively. The sensor based on the polymer-GO diode is cost-effective, environmentally friendly, and easy to fabricate using low-cost solution-processing methods.
\end{abstract}

\section{Introduction}

Ammonia has been widely used in agricultural, medical, and industrial applications. ${ }^{1,2} \mathrm{NH}_{3}$ is a colorless and toxic gas that can cause severe problems for human health. On the other hand, $\mathrm{N}_{2} \& \mathrm{O}_{2}$ has been detected for comparison with $\mathrm{NH}_{3}$ gas. To measure $\mathrm{NH}_{3}$ in the atmosphere, fabricating an efficient and reliable $\mathrm{NH}_{3}$ sensor that has a high sensitivity, rapid detection response, and rapid recovery time is essential. Solid-state $\mathrm{NH}_{3}$ gas sensors have been the focus of recent research. ${ }^{3,4}$ Schottky diode heterojunctions are promising candidates for sensing a low concentration of gases, since upon gas exposure, a small change in the chemical composition of the layers, contact barriers, or even the interfaces can lead to a huge difference in the diode response or current-voltage $(I-V)$ characteristics. $^{2,4-7}$ Recently, Chen et al. have reported a Pt/AlGaN/GaN Schottky diode that detects $\mathrm{NH}_{3}$ at $35 \mathrm{ppm}$ with a response time approaching $7 \mathrm{~min}$ and a sensitivity of 13.1 . $^{4}$ However, the reported high sensitivity was achieved at elevated temperatures, $50{ }^{\circ} \mathrm{C}(423 \mathrm{~K})$ instead of room temperature. A Schottky diodetype ammonia sensor with high sensitivity, rapid detection response and rapid recovery time is still required. Other kinds of polymer (PTFE, PVDF, PANI) include conducting polymers with high conductivity, environmental stability, optical transparency, and moderate redox potential. ${ }^{\mathbf{8 - 1 4}}$ Recently, gas sensors based on PTFE, PVDF, or PANI have been introduced as

Department of Advanced Materials Science \& Engineering, Hanseo University, Seosan-si, Chungnam, 356-706, Korea. E-mail: wc_oh@hanseo.ac.kr; Fax: +82-41688-3352; Tel: $+82-41-660-1337$ promising gas detectors with efficient properties, such as a facile fabrication process, low cost, high sensitivity, and fast response time..$^{3,15,16}$ It is well-known that (PTFE, PVDF, PANI) are conductive polymers with high stability in air, suggesting their potential in sensing applications. For instance, Lin et al. fabricated a nitric oxide (NO) gas sensor by using a (PTFE, PVDF, PANI) modified electrode. ${ }^{17}$ However, the response and recovery time were long, about a few minutes. ${ }^{17}$ Mixing (PTFE, PVDF, PANI) with carbon nanostructures, such as graphene sheets (and its derivatives), creates a composite material with stronger mechanical strength and better electrical properties because of its high surface to volume ratio. ${ }^{\mathbf{8 - 1 4}}$ Water-soluble graphene oxide (GO) has a unique heterogeneous electronic structure because of the presence of mixed $\mathrm{sp}^{2}$ and $\mathrm{sp}^{3}$ hybridizations. ${ }^{\mathbf{9} 18-20}$ Poly-GO composites have been recently employed as electrical contacts in organic solar cells ${ }^{\mathbf{9 , 2 1 , 2 2}}$ and light-emitting diodes, ${ }^{18,20}$ as an electrode in batteries, ${ }^{\mathbf{2 3}, 24}$ within the hydrogen evolution reaction, ${ }^{25}$ as supercapacitors, ${ }^{26}$ as gas and chemical sensors ${ }^{27-32}$ and as transistors. ${ }^{33}$ For sensing applications, poly-GO composites hold great promise because of the large surface area of the GO flakes. ${ }^{9-13}$ The GO sheets provide a better platform to absorb the target gas and to provide electron transfer within the conductive network of (PTFE, PVDF, PANI). Besides the absorption of gas on the surface of the hybrid layer, the interfaces between the composite and semiconductor in diode-based gas sensors can be used in the detection of gas, leading to a higher response than with pure (PTFE, PVDF, PANI) based gas sensors. Here, we mixed GO sheets in different concentrations with (PTFE, PVDF, PANI) water-based suspensions and used the composite as an ammonia-sensing layer in 
a $\mathrm{BiVO}_{4}$ Schottky diode. The GO sheets were prepared by a modified Hummer's method. ${ }^{20,34,35}$ The diode parameters and sensing performance improved by adding an infinitesimal amount of GO into (PTFE, PVDF, PANI). At a low GO loading of $0.04 \mathrm{wt} \%$ in (PTFE, PVDF, PANI), the diode showed a sensitivity of 194 to $201 \mathrm{ppm}$ ammonia in the atmosphere at room temperature $\left(25^{\circ} \mathrm{C}\right)$, with a response and recovery time of 95 and $121 \mathrm{~s}$, respectively. In this work, a new class of high electron mobility Schottky diode gas sensor is presented as a chemical sensing platform with high performance, good stability, low limit of detection down to ppb level and functionality at room temperature. The key components in our design of the device are a Schottky contact material on an organic/inorganic diode formed by different kinds of polymer (PTFE, PVDF, PANI) deposited on top of $\mathrm{BiVO}_{4}$. Gas sensors based on GO have shown high sensitivity at room temperature and rapid response. The sensing mechanism of the device in this work is based on the coupling effect between the GO nanosheets and the (PTFE, PVDF, PANI) deposited on top of $\mathrm{BiVO}_{4}$ surface, while the GO nanosheets showed p-type characteristics mainly caused by exposure to the ambient environment and their van der Waals heterostructure with the polymer layers, forming a Schottky diode with $\mathrm{BiVO}_{4}$. When the diode sensors were introduced to $\mathrm{NH}_{3}$ gases for investigation of their sensor response, the Schottky diode sensor with an organic/inorganic diode formed by different kinds of polymer (PTFE, PVDF, PANI) deposited on top of $\mathrm{BiVO}_{4}$ responded more rapidly and strongly to $\mathrm{NH}_{3}$ gases, down to $\mathrm{ppb}$ levels. This heterostructuring of a GO active Schottky diode based on an organic/inorganic diode formed by different kinds of polymer (PTFE, PVDF, PANI) deposited on top of $\mathrm{BiVO}_{4}$ sensing layer will form the next generation of gas sensor applications. Due to its gas detection capabilities at room temperature, the Schottky diode gas sensor has great potential for integration into portable wireless electronic systems for a variety of applications.

\section{Experimental}

Graphite flakes, hydrogen peroxide, potassium permanganate $\left(\mathrm{KMnO}_{4}\right)$, and poly(3,4-ethylenedioxythiophene): poly(styrenesulfonate) (PTFE, PVDF, PANI), $1.3 \mathrm{wt} \%$ dispersion in $\mathrm{H}_{2} \mathrm{O}$, conductive grade, $\mathrm{pH} 10$ were purchased from Sigma Aldrich. Sulfuric acid, hydrochloric acid, $\left(\mathrm{NH}_{3}, \mathrm{~N}_{2}, \mathrm{O}_{2}\right)$, methanol, ethanol, acetone, and dimethyl sulfoxide (DMSO) were purchased from Merck and used without any purification. GO was synthesized using a modified Hummer's method with expanded graphite. ${ }^{\mathbf{1 8 , 1 9}}$ The obtained GO was diluted in deionized water $\left(1 \mathrm{mg} \mathrm{ml}^{-1}\right)$. The solution was then sonicated for $20 \mathrm{~min}$ in a bath sonicator, followed by centrifugation at $5000 \mathrm{rpm}$ for $5 \mathrm{~min}$. The GO sheets produced with this procedure had a lateral size of $60 \mathrm{~mm}$. After filtration of (PTFE, PVDF, PANI) ( $0.5 \mathrm{~mm}$ pore size), different concentrations of GO $(0.00$, $0.02,0.04,0.06$, and $0.08 \mathrm{wt} \%$ ) along with $6 \mathrm{wt} \%$ of dimethyl sulfoxide (DMSO) were added and stirred for $6 \mathrm{~h}$. The device structure of the poly-GO/BiVO 4 gas sensor is illustrated in Fig. 1a. Ohmic back contacts to the $\mathrm{BiVO}_{4}$ wafer $\left(1 \times 1 \mathrm{~cm}^{2}\right)$ (with impurity concentration of $1.5 \times 10^{18}$ atoms $\mathrm{cm}^{3}$ ) were

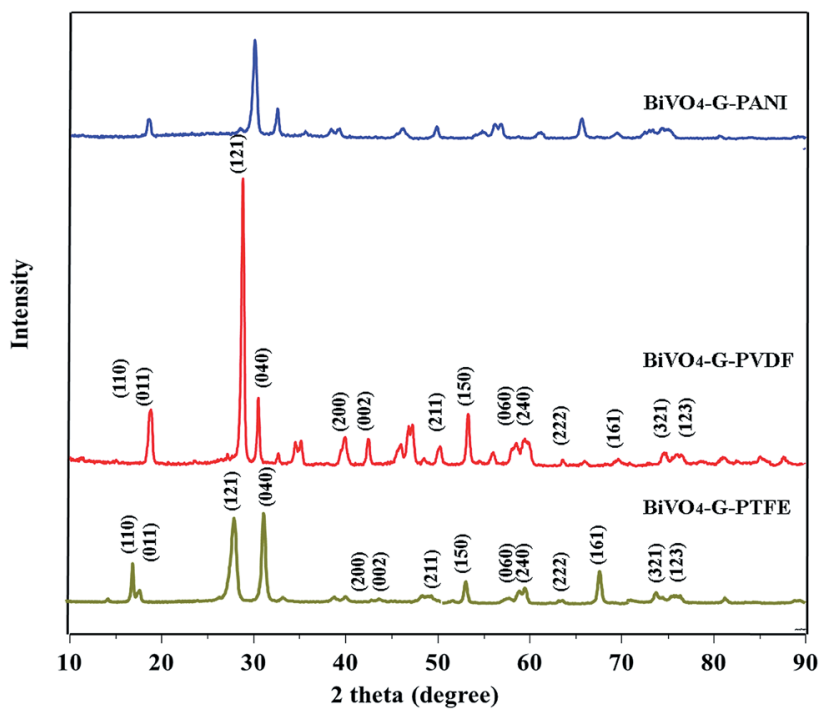

Fig. 1 XRD data of $\mathrm{BiVO}_{4}-\mathrm{GO}-\mathrm{PTFE} ; \mathrm{BiVO}_{4}-\mathrm{GO}-\mathrm{PVDF}$ and $\mathrm{BiVO}_{4}-$ GO-PANI sample.

made using Au-Ge alloy (100 nm) physical vapor deposition on the reverse side of the $\mathrm{BiVO}_{4}$ wafers. The back contacts were then annealed at $350{ }^{\circ} \mathrm{C}$ under a nitrogen atmosphere for $3 \mathrm{~min}$. Poly-GO with different GO loading ratios (0.02, 0.04, 0.06, 0.08 wt\%), were spin-coated on the top surface of n-type epitaxial $\mathrm{BiVO}_{4}$. The comparison $\mathrm{BiVO}_{4}$ was cleaned prior to poly-GO deposition using Piranha solution. The devices were then dried for $60 \mathrm{~min}$ in a furnace (Exciton, EX1200-4L) at $80{ }^{\circ} \mathrm{C}$ under a nitrogen atmosphere. Ohmic top metal contacts were then made by vacuum evaporation $\left(10^{-5} \mathrm{mbar}\right)$ of silver (200 $\mathrm{nm}$ ) on top of the active layer. Freeze-dried GO samples were examined with scanning electron microscopy (SEM, JEOL-6390). Transmission electron microscopy (TEM) images were obtained using a JEM-2200 FS at $200 \mathrm{kV}$. Fourier-transform infrared spectroscopy (FTIR) analysis was performed using a Bruker, IFS$66 / \mathrm{S}$ over the wavenumber range of $4000-400$ per $\mathrm{cm}$. X-Ray diffraction (XRD) studies were performed to characterize the interlayer spacing of the GO samples using a powder XRD system (Philips1825) with $\mathrm{Cu} \mathrm{K} \alpha$ radiation $(\lambda 1 / 40.154 \mathrm{~nm}$ ), operating at $40 \mathrm{keV}$ and with a cathode current of $20 \mathrm{~mA}$. The thickness of the poly-GO thin films was obtained by SEM crosssection measurements. The sensors were placed inside a homemade test chamber, as schematically illustrated. The chamber was connected to a mixer where the ammonia gas and highly purified nitrogen (99\%) were mixed. Mass flow controllers (MFC, Alicat Scientific, Tucson, AZ, USA) were used to modulate the flow rates of ammonia and nitrogen. The $I-V$ measurements of the sensors were made using a Keithley 238 high current source measure unit. The forward biased $I-V$ characteristics of the junction before and after exposure to $\mathrm{NH}_{3}$ were recorded. The maximum current change at a fixed voltage (b $1.5 \mathrm{~V}$ ) was used to determine the sensitivity of the sensors. The sensitivity was defined using sensitivity $\frac{1}{4} I_{\text {air }} / I_{\text {gas }}$, by measuring the currents of the poly-GO/BiVO ${ }_{4}$ heterojunction in air and in the presence of $\mathrm{NH}_{3}$. The standard experiments were carried out at room temperature $\left(25^{\circ} \mathrm{C}\right)$ and a relative humidity of $15 \%$. 


\section{Characterization of GO sheets}

The XRD spectrum of the as-prepared GO is given in Fig. 1. The sharp peak at $2 \theta=10.1$ confirms the $d$-spacing of $8.78 \AA$, thereby suggesting that the GO sheets are interlinked via functional (carboxyl and hydroxyl) groups. Fig. 2b shows the FTIR spectra of the prepared GO. The vibration modes of the GO sample were assigned in accordance with previously reported work. ${ }^{16,21}$ The characteristic peaks of the as-prepared GO were assigned at $3423 \mathrm{~cm}^{-1}$ (O-H stretching vibrations are assigned to the hydroxyl groups on the GO surface), $1742 \mathrm{~cm}^{-1}$ (C55O groups in carbonyl and carboxyl moieties), $1631 \mathrm{~cm}^{-1}$ (skeletal vibrations of unoxidized graphitic domains (C55C)), $1416 \mathrm{~cm}^{-1}$ (C-O carboxy), $1220 \mathrm{~cm}^{-1}$ (C-O epoxy), and $1150 \mathrm{~cm}^{-1}$ (C-O stretching vibrations). ${ }^{16,21}$ An SEM image of the as-prepared GO is given in Fig. 2. The depicted GO sheets were measured to have a lateral size in the range of 40-80 $\mu \mathrm{m}$. However, smaller fragments of GO sheet with a lateral size between $20-30 \mu \mathrm{m}$ were also observed. According to the cross-section image of the Schottky diode the thickness of the (PTFE, PVDF, PANI)-GO is almost $950 \mathrm{~nm}$.

In addition, such an amorphous structure is also revealed by TEM investigation, as shown in Fig. 3. This poly-GO-BiVO 4 was found to actually consist of many smaller nanoparticles with a size of about $50 \mathrm{~nm}$. TEM imagery (Fig. 3) was recorded on the edge of the nanoparticle. The clear lattice fringe specifies the high-crystallinity and single-crystalline behaviour of the nanoparticles. The interplanar spacing is $0.309 \mathrm{~nm}$, which corresponds to the (121) plane of monoclinic $\mathrm{BiVO}_{4}$. It has also been reported that small grain size and high crystallinity endowed increased photocatalytic activity for increased reactive sites, and promoted electron-hole separation efficiency. Thus, the as-prepared nano poly-GO- $\mathrm{BiVO}_{4}$ was expected to show enhanced sensing performance.

Raman spectroscopy is one of the most helpful tools to characterize carbon-based materials. Fig. 4 shows the Raman spectra of selective poly-BiVO $4-\mathrm{GO}$ composites (a) $\mathrm{BiVO}_{4}-\mathrm{GO}-\mathrm{PVDF}$; (b) $\mathrm{BiVO}_{4}-\mathrm{GO}-\mathrm{PTFE}$ and (c) $\mathrm{BiVO}_{4}-\mathrm{GO}-\mathrm{PANI}$. Consistent with the $\mathrm{XRD}$ results, the Raman spectra show that $\mathrm{BiVO}_{4}$ has a monoclinic phase, on the basis of the characteristic stretching vibrations and bending vibrations of the $\mathrm{VO}_{4}{ }^{3-}$ tetrahedron. The Raman spectrum of PANI-BiVO ${ }_{4}-\mathrm{GO}$ demonstrates one characteristic band at $1600 \mathrm{~cm}^{-1}$, corresponding to the $\mathrm{G}$ band of GO, accordingly. In comparison, the $\mathrm{BiVO}_{4}-\mathrm{GO}-\mathrm{PTFE}$ and $\mathrm{BiVO}_{4}-\mathrm{GO}-$ PVDF composites show that the $\mathrm{G}$ band is a little red shifted to $1606 \mathrm{~cm}^{-1}$ which may, accordingly, be caused by the changed surface strain, due to the contact between $\mathrm{GO}$ and $\mathrm{BiVO}_{4}$. This phenomenon is consistent with that observed in the hydrothermal in situ preparation of the poly- $\mathrm{BiVO}_{4}-\mathrm{GO}$ composites, where a $\mathrm{D} / \mathrm{G}$ ratio close to zero suggests the effective combination of $\mathrm{BiVO}_{4}-\mathrm{GO}$ with PANI polymer and others.

The composition of the poly- $\mathrm{BiVO}_{4}-\mathrm{GO}$ heterogeneous nanostructures has been further investigated using X-ray photoelectron spectroscopy (XPS). Fig. 5 shows the highresolution XPS spectra of the as-prepared poly- $\mathrm{BiVO}_{4}-\mathrm{GO}$
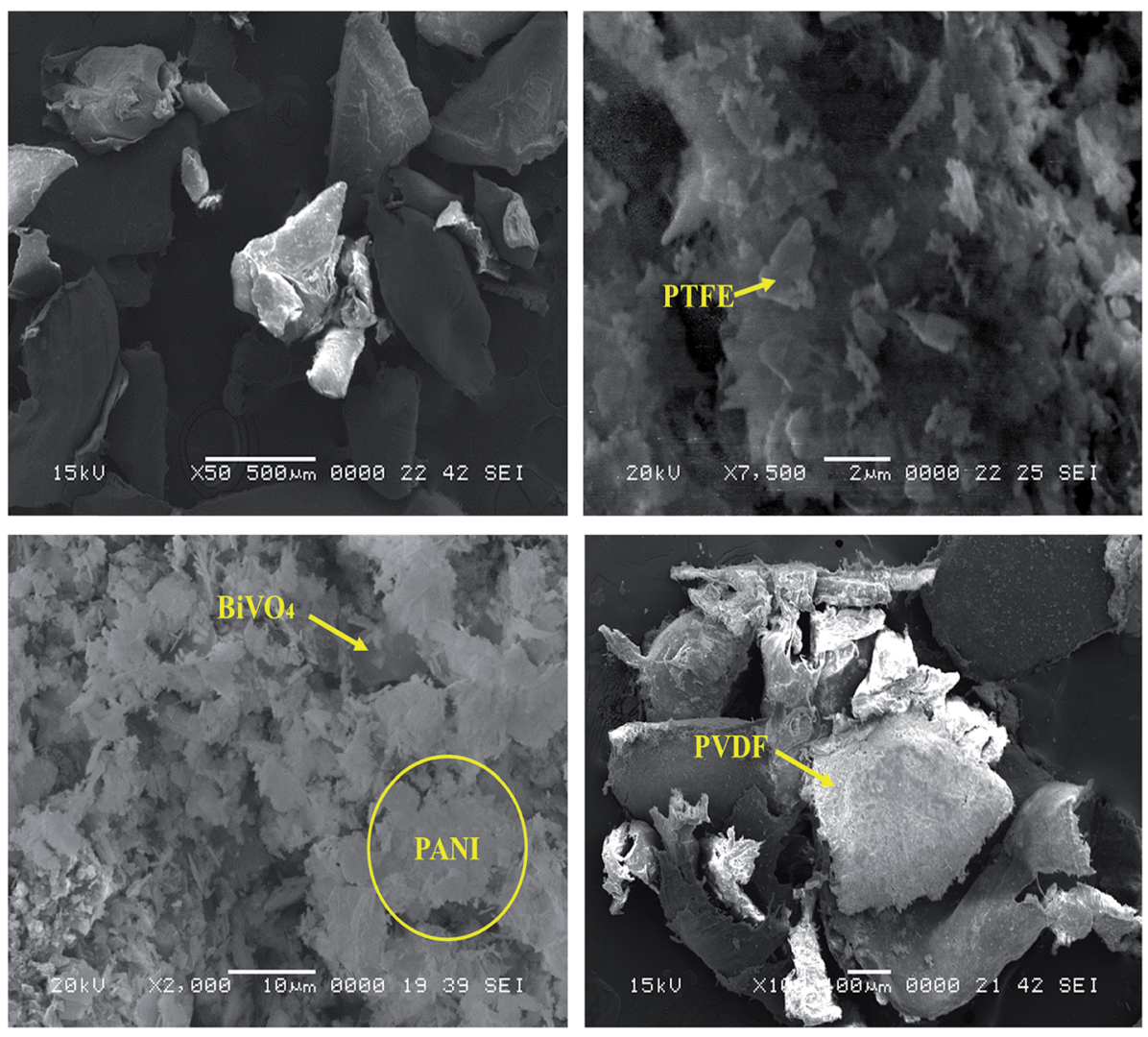

Fig. 2 SEM image of (a) $\mathrm{BiVO}_{4}-\mathrm{GO}-\mathrm{PVDF}$; (b) $\mathrm{BiVO}_{4}-\mathrm{GO}-\mathrm{PTFE}$ and (c) $\mathrm{BiVO}_{4}-\mathrm{GO}-\mathrm{PANI}$ (d) $\mathrm{BiVO}_{4}-\mathrm{GO}-\mathrm{PVDF}$ sample. 

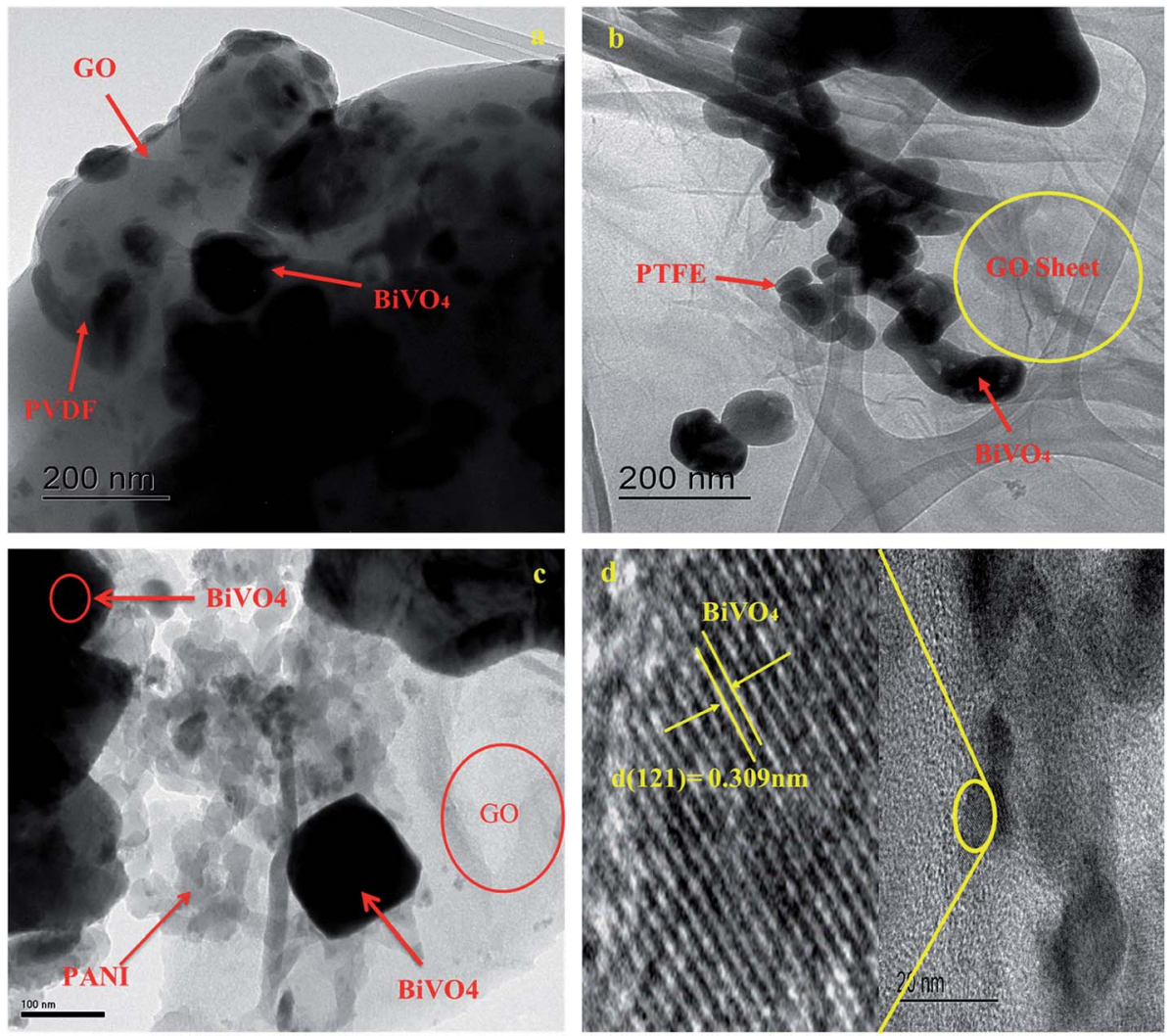

Fig. 3 TEM \& HRTEM image of (a) $\mathrm{BiVO}_{4}-\mathrm{GO}-\mathrm{PVDF}$; (b) $\mathrm{BiVO}_{4}-\mathrm{GO}-\mathrm{PTFE}$ and (c) $\mathrm{BiVO}_{4}-\mathrm{GO}-\mathrm{PANI}$ (d) HRTEM image.

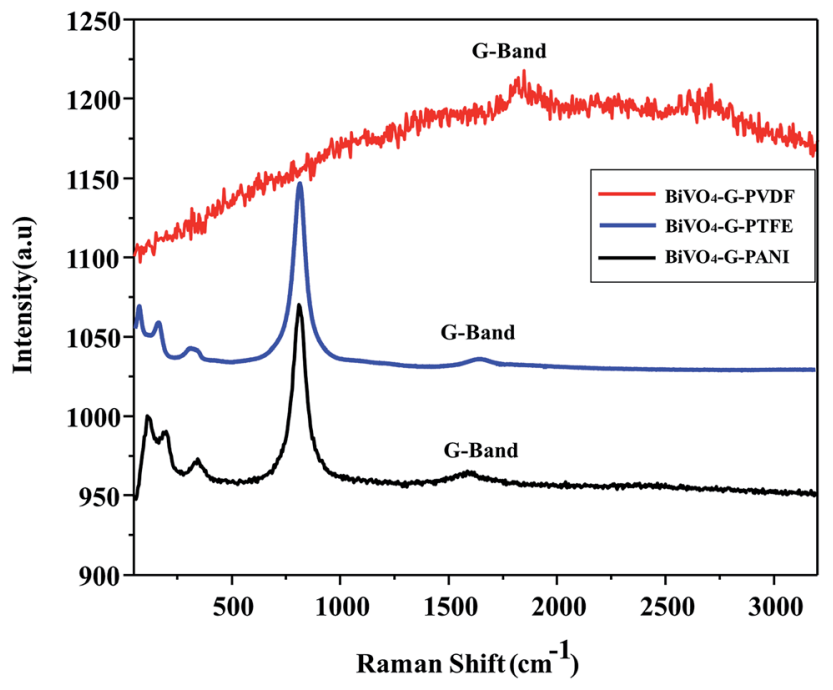

Fig. 4 TEM \& HRTEM image of (a) $\mathrm{BiVO}_{4}-\mathrm{GO}-\mathrm{PVDF}$; (b) $\mathrm{BiVO}_{4}-\mathrm{GO}-$ PTFE and (c) $\mathrm{BiVO}_{4}-\mathrm{GO}-\mathrm{PANI}$.

heterogeneous nanostructures. Fig. 5a shows that the binding energies are located at about (160.1 and 166.5) eV, corresponding to the Bi4f $f_{5 / 2}$ and Bi4f $f_{7 / 2}$ bands, respectively. The XPS spectrum of the O1s band, indicating that different oxygen species exist on the surface of $\mathrm{PANI}-\mathrm{BiVO}_{4}-\mathrm{GO}$ heterogeneous nanostructures. The binding energies located at about (532.2 and 533.1) eV are ascribed to the O1s band of the lattice oxygen of GO crystallites and the O1s band of the lattice oxygen of $\mathrm{BiVO}_{4}$ crystallites, respectively. In the high-resolution XPS spectrum of the V2p band, the peaks at about (527 and 518.5) eV correspond to V2 $\mathrm{p}_{1 / 2}$ and $\mathrm{V} 2 \mathrm{p}_{3 / 2}$ bands, respectively. The XPS spectrum of the C1s band presented in Fig. 5a, clearly shows one peak located at $287.3 \mathrm{eV}$, which corresponds to the $\mathrm{C} 1 \mathrm{~s}$ bands of GO and PANI crystallites, respectively. The C1s peak is accompanied by two satellites that are evident on the highbinding-energy side, denoted as peaks I and II, which are located at about (287.3 and 287.5) eV, respectively. The main peak in the XPS spectrum of the N1s band is known to be characteristic of $\mathrm{N}^{2-}$; the shake-up satellite peaks are evident, and are diagnostic of an open $3 \mathrm{p}^{4}$ shell of the $\mathrm{N}^{2-}$ state, indicating the presence of PANI at the surface. The fact that XRD does not show evidence of a PANI phase while XPS shows the surface presence of $\mathrm{N}^{2-}$ ions suggests that $-\mathrm{NH}_{2}$ is present only on the surface of the PANI nanocrystals, and forms a very thin amorphous outer shell. On the basis of the above experimental results of XRD, TEM, and XPS, it can be deduced that the $\mathrm{N}$ element exists in the form of $\mathrm{NH}^{-}$on the surface of PANI$\mathrm{BiVO}_{4}-\mathrm{GO}$ heterogeneous nanostructures.

\section{I-V characteristics of the poly-GO/ $\mathrm{BiVO}_{4}$ Schottky diode}

The forward bias $I-V$ characteristics of the poly-GO-BiVO Schottky diodes fabricated with different GO contents show 

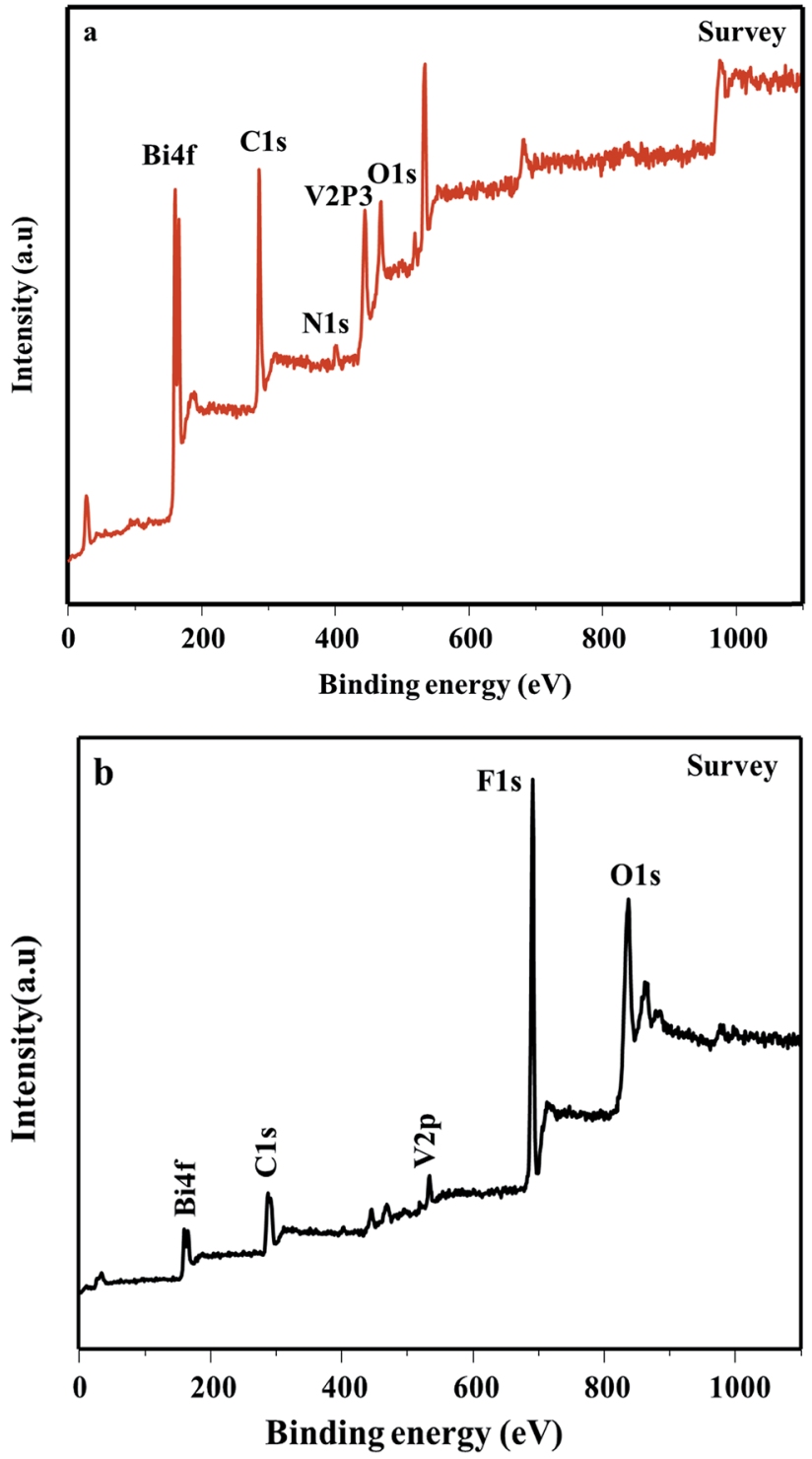

Fig. 5 XPS data of (a) $\mathrm{BiVO}_{4}-\mathrm{GO}-\mathrm{PANI} \&$ (b) $\mathrm{BiVO}_{4}-\mathrm{GO}-\mathrm{PVDF}$.

a decent rectifying behavior. The forward bias increases via doping the (PTFE, PVDF, PANI) solution with different amounts of GO. The maximum forward bias current was measured for $0.04 \mathrm{wt} \% \mathrm{GO}$, which shows the highest conductivity. However, if one adds an excessive amount of GO, up to $0.40 \mathrm{wt} \%$, the diode behavior degrades. The observed behavior in diode performance can be rationalized via changing the conductivity of (PTFE, PVDF, PANI) by adding GO. The conductivity increases with the addition of $\mathrm{GO}$, reaches a maximum value at $0.04 \mathrm{wt} \%$, and drops by further addition of GO (as will be explained in detail in the next section). Therefore, because of the reduction of conductivity at higher loading, the diode performance deteriorates.

\section{Ammonia-sensing properties}

The $\mathrm{NH}_{3}$ response of the poly-GO/BiVO 4 Schottky diode at an applied potential of $\mathrm{p} 1.5 \mathrm{~V}$ is shown in Fig. 6. The diode at

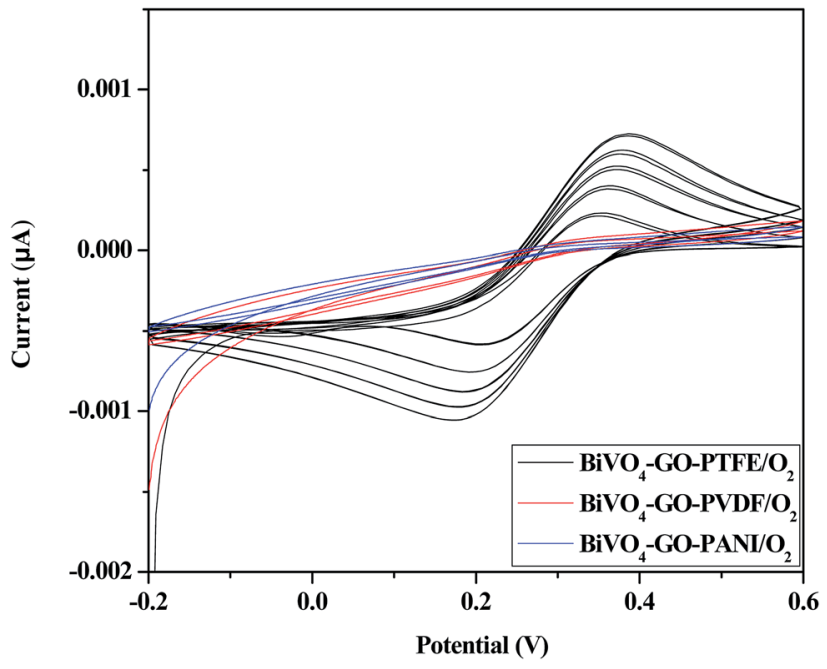

Fig. 6 Optimal manufacturing process for the polymer-based gassensor. Cyclic voltammogram of $\mathrm{BiVO}_{4}-\mathrm{GO}-\mathrm{PTFE} / \mathrm{O}_{2} ; \mathrm{BiVO}_{4}-\mathrm{GO}-$ $\mathrm{PVDF} / \mathrm{O}_{2}$ and $\mathrm{BiVO}_{4}-\mathrm{GO}-\mathrm{PANI} / \mathrm{O}_{2}$ after flowing $\mathrm{O}_{2}$ gas.

$0 \mathrm{wt} \%$ GO showed a weak response in sensitivity when exposed to different $\mathrm{NH}_{3}$ concentrations. However, as the concentration of GO increased to $0.04 \mathrm{wt} \%$, the sensitivity of the diode increased. Upon further increasing of GO in the (PTFE, PVDF, PANI) solution, the sensitivity dropped again to the level of pristine (PTFE, PVDF, PANI). The sensitivity value of the polyGO $(0.04 \mathrm{wt} \%) / \mathrm{BiVO}_{4}$ heterojunction was measured to be 3654 in $1800 \mathrm{ppm} \mathrm{NH}_{3}$, which is nearly two times higher than the pristine (PTFE, PVDF, PANI). The conductivity of the sensing layer as a function of GO concentration is shown in Fig. 7. This improvement in sensitivity is attributed to the increase in conductivity with added GO (0.04 wt $\%)$ nanosheets from 650 $\left(\mathrm{S} \mathrm{cm}^{-1}\right)$ in $0 \mathrm{wt} \%$ GO to $950\left(\mathrm{~S} \mathrm{~cm}^{-1}\right)$ in $0.04 \mathrm{wt} \%$ (Fig. 8). The reason for the increase in conductivity as well as the

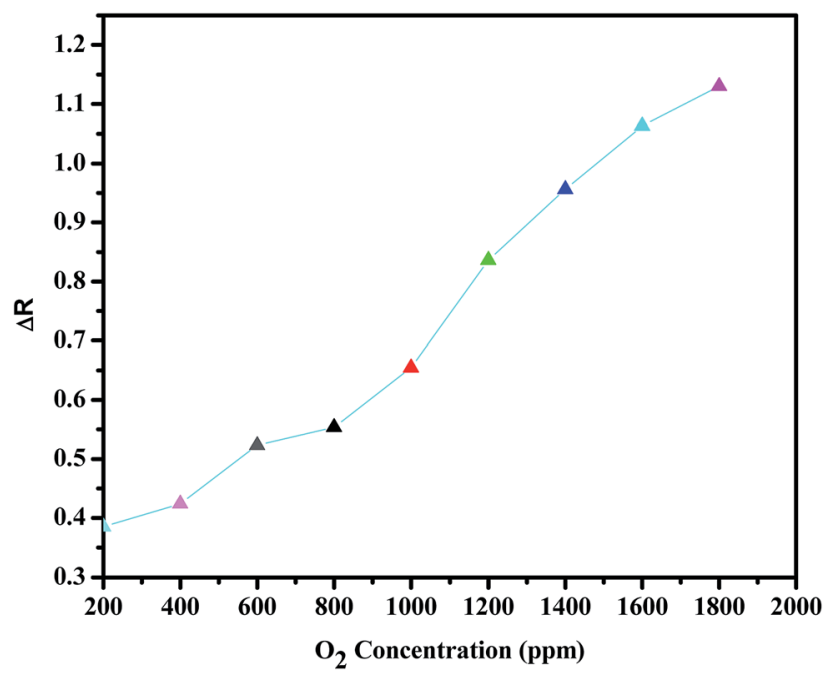

Fig. 7 Concentration dependence of the electrical response $(\Delta R)$ for $\mathrm{BiVO}_{4}-\mathrm{GO}-\mathrm{PANI}$ sample in response to increasing levels of $\mathrm{O}_{2}$ concentration (ppm). 


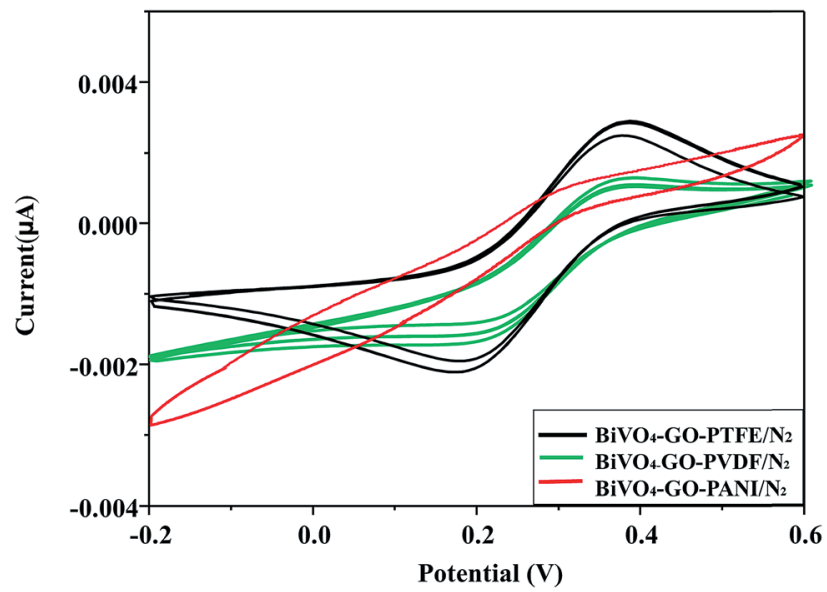

Fig. 8 Optimal manufacturing process for the polymer-based gassensor. Cyclic voltammogram of $\mathrm{BiVO}_{4}-\mathrm{GO}-\mathrm{PTFE} / \mathrm{N}_{2} ; \mathrm{BiVO}_{4}-\mathrm{GO}-$ $P V D F / N_{2}$ and $B_{V} O_{4}-G O-P A N I / N_{2}$ after flowing $N_{2}$ gas.

morphological study was given in detail. ${ }^{20,36}$ Briefly, because of several functional groups (such as $-\mathrm{COOH}$ and $-\mathrm{OH}$ ) on $\mathrm{GO}$ nanosheets, positively charged PTFE, PVDF, PANI chains adsorb on the surface of GO nanosheets. The absorption of PTFE, PVDF, PANI chains induces a phase separation between PTFE, PVDF, PANI chains, which enlarges the PTFE, PVDF, PANI domain (Fig. 9). Moreover, as a result of coulombic repulsions among the positive charges in the PTFE, PVDF, PANI chains adsorbed on the surface of the GO, PTFE, PVDF, PANI chains form a linear conformation which increases the number of active sites available to the analyte (Fig. 10). ${ }^{20,36}$ In addition, the formation of linear PTFE, PVDF, PANI chains and the phase separation between PTFE, PVDF, PANI enlarge the PTFE, PVDF, PANI-rich domains with longer conductive pathways, leading to an increase in carrier mobility. On the other hand, by further increasing the GO content (more than $0.04 \mathrm{wt} \%$ ), more

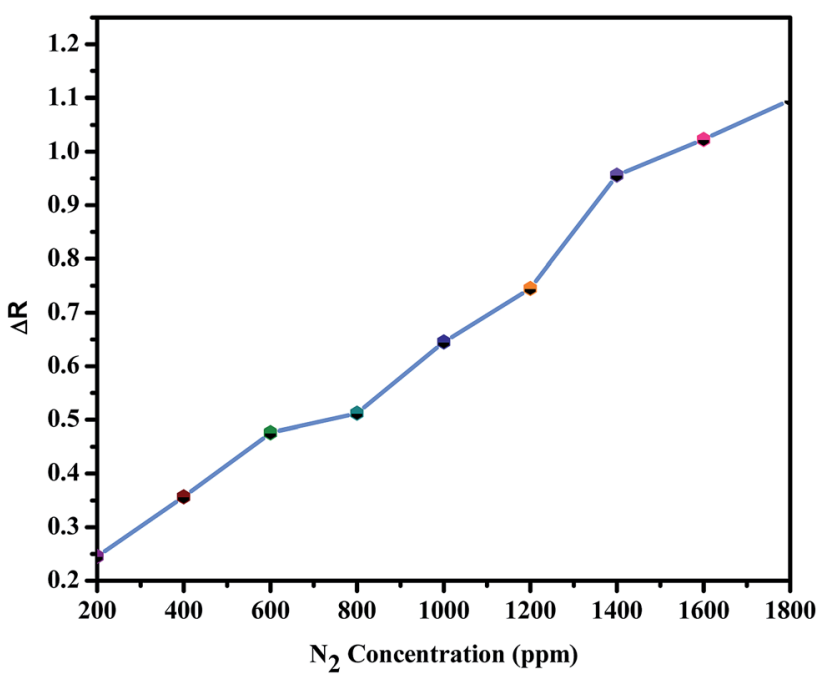

Fig. 9 Concentration dependence of the electrical response $(\Delta R)$ for $\mathrm{BiVO}_{4}-\mathrm{GO}-\mathrm{PANI}$ sample in response to increasing levels of $\mathrm{N}_{2}$ concentration (ppm).

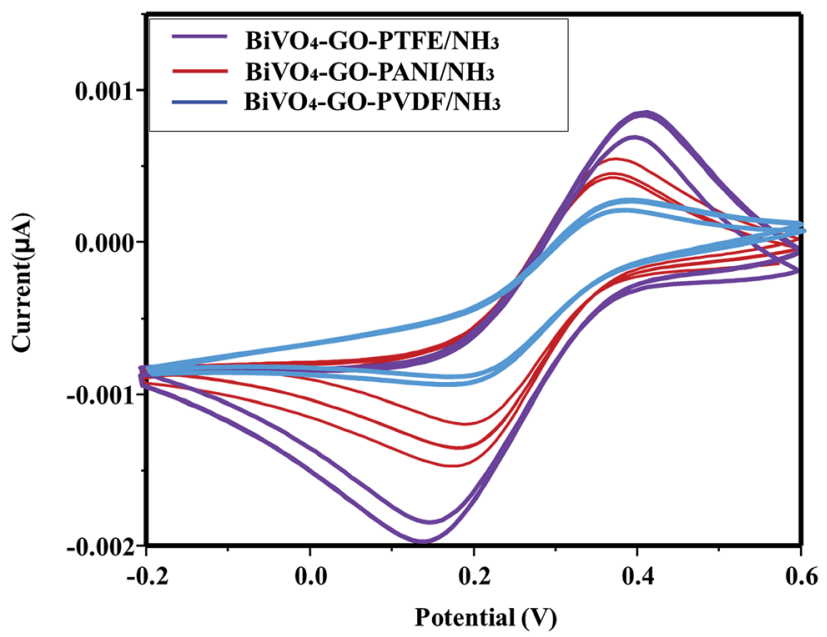

Fig. 10 Optimal manufacturing process for the polymer-based gassensor. Cyclic voltammogram of $\mathrm{BiVO}_{4}-\mathrm{GO}-\mathrm{PTFE} / \mathrm{NH}_{3}$; $\mathrm{BiVO}_{4}-\mathrm{GO}-$ $\mathrm{PANI} / \mathrm{NH}_{3}$ and $\mathrm{BiVO}_{4}-\mathrm{GO}-\mathrm{PVDF} / \mathrm{NH}_{3}$ after flowing $\mathrm{NH}_{3}$ gas.

functional groups on GO sheets can bond with fewer PTFE, PVDF, PANI chains by coulombic attraction. Thus, because there are fewer PTFE, PVDF, PANI chains distributed in GO nanosheets, the coulombic repulsions between the positive charges in the PTFE, PVDF, PANI chains are reduced. As a result of less coulombic repulsion, the PTFE, PVDF, PANI chains on the surface of GO again form a coil structure (Fig. 10). Therefore, the carrier mobility and the number of available active sites for interacting with analyte molecules will decrease and the performance of the $\left(\mathrm{NH}_{3}, \mathrm{~N}_{2}, \mathrm{O}_{2}\right)$ sensor will diminish. Indeed, the concentration of GO in (PTFE, PVDF, PANI) has an important role in the performance of the sensor. Moreover, the addition of GO into (PTFE, PVDF, PANI) has a synergistic effect that increases the response to $\left(\mathrm{NH}_{3}, \mathrm{~N}_{2}, \mathrm{O}_{2}\right)$. In our previous work, we investigated the sensing mechanism of (PTFE, PVDF, PANI)-GO exposed to volatile organic compound (VOC) gases. ${ }^{16}$ Briefly, the $\mathrm{NH}_{3}$ gas molecule acts like an electron donor. When the (PTFE, PVDF, PANI)-GO sensing layer is exposed to an electron donor (like an $\mathrm{NH}_{3}$ molecule), the charge carriers (holes) in a p-type semiconductor like (PTFE, PVDF, PANI)-GO decrease, increasing film resistivity. In addition, $\mathrm{NH}_{3}$ molecules interact not only with the (PTFE, PVDF, PANI) and GO, but also by $\pi-\pi$ bonding interactions between GO and (PTFE, PVDF, PANI). The interaction between $\left(\mathrm{NH}_{3}, \mathrm{~N}_{2}, \mathrm{O}_{2}\right)$ polar molecules and (PTFE, PVDF, PANI)-GO leads to a charge transfer across delocalized $\pi$ electrons, resulting in the measured improved gaseous detection properties. ${ }^{16,20}$ In the next step, roomtemperature $I-V$ characteristics of the (PTFE, PVDF, PANI)-GO $(0.04 \mathrm{wt} \%) / \mathrm{BiVO}_{4}$ heterojunction at different concentrations (ppm) of $\mathrm{NH}_{3}$ were measured, as presented in Fig. 11. The $\left(\mathrm{NH}_{3}\right.$, $\mathrm{N}_{2}, \mathrm{O}_{2}$ ) concentration was varied systematically between 200$1800 \mathrm{ppm}$. The sensor response (\%) versus $\left(\mathrm{NH}_{3}, \mathrm{~N}_{2}, \mathrm{O}_{2}\right)$ concentration was extracted from Fig. 11. The sensor response increased from 26 to 3654 with increasing $\mathrm{NH}_{3}$ concentration from 200 to $1800 \mathrm{ppm}$. The detection limit of $\left(\mathrm{NH}_{3}, \mathrm{~N}_{2}, \mathrm{O}_{2}\right)$ for the poly-GO $(0.04 \mathrm{wt} \%) / \mathrm{BiVO}_{4}$ heterojunction gas sensor was 


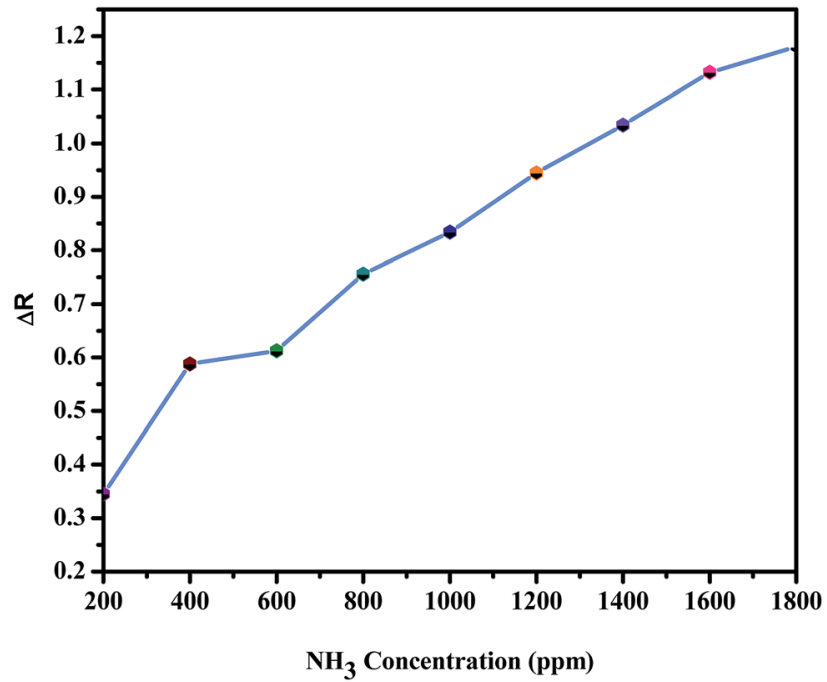

Fig. 11 Concentration dependence of the electrical response $(\Delta R)$ for $\mathrm{BiVO}_{4}-\mathrm{GO}-\mathrm{PVDF}$ sample in response to increasing levels of $\mathrm{NH}_{3}$ concentration (ppm).

thus estimated to be $200 \mathrm{ppm}$ at the room temperature. As the $\left(\mathrm{NH}_{3}, \mathrm{~N}_{2}, \mathrm{O}_{2}\right)$ concentration reaches $1800 \mathrm{ppm}$, the response of the sensor saturates, because of the chemical nature of $\mathrm{NH}_{3}$ and the reaction products, which may not diffuse away from the interface immediately upon completion of the reaction. ${ }^{3,5}$ The response time of the sensor is shown in Fig. 12. The timedependent response was measured at a constant voltage of $1.5 \mathrm{~V}$. The resistance difference $(\Delta R)$ with different concentrations of $\mathrm{NH}_{3}$ gas $(40,60,80$ and $100 \mathrm{ppm})$ is illustrated in Fig. 12. The maximum sensitivity is reached within 8 seconds, and the recovery time approaches 101 seconds.

\section{Temperature effects}

Compared to metal oxide-based gas sensors, ${ }^{34,37,38}$ the poly-GO thin-film gas sensors operate at lower temperatures. The

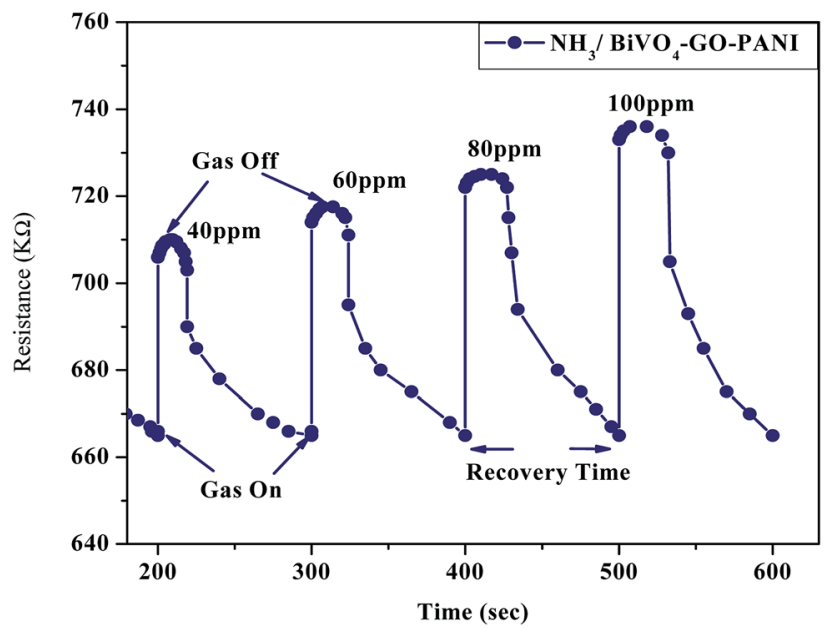

Fig. 12 Dynamic response of the $\mathrm{BiVO}_{4}-\mathrm{GO}-\mathrm{PANI}$ gas sensor with different concentration of $\mathrm{NH}_{3}$ gas.

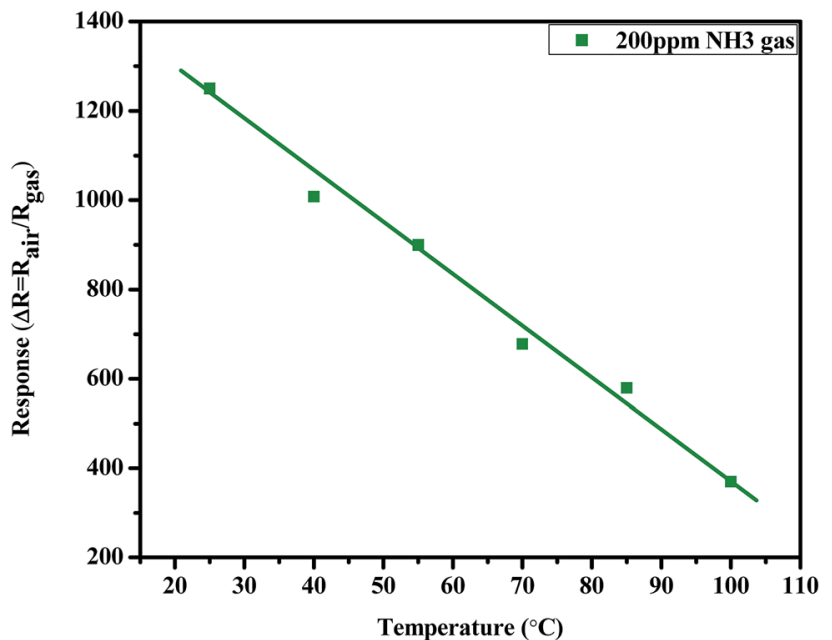

Fig. 13 Effect of temperature on the $\mathrm{NH}_{3}$ gas sensing response of the $\mathrm{BiVO}_{4}-\mathrm{GO}(0.04 \mathrm{wt} \%)-\mathrm{PANI}$ Schottky diode sensor.

temperature response of the sensor for $200 \mathrm{ppm} \mathrm{NH}_{3}$ is given in Fig. 13. The interaction between the poly-GO thin film and $\mathrm{NH}_{3}$ is exothermic; hence the activation energy of desorption is larger than that of the adsorption. ${ }^{35}$ The increase in temperature facilitates both gas adsorption and desorption, but favors the process with a higher activation energy. ${ }^{\mathbf{1 7 , 3 9 - 4 1}}$ Therefore the observation of a longer recovery time, as well as the decrease in response at higher temperatures, is attributed to a high $\mathrm{NH}_{3}$ desorption rate. ${ }^{15,42,43}$

\section{Stability}

Fig. 14 indicates the stability of the poly-GO $(0.04 \mathrm{wt} \%) / \mathrm{BiVO}_{4}$ gas sensor exposed to $35 \mathrm{ppm} \mathrm{NH}_{3}, \mathrm{~N}_{2}, \mathrm{O}_{2}$ for 7 days at room temperature $\left(25{ }^{\circ} \mathrm{C}\right.$ and $\left.17 \% \mathrm{RH}\right)$. The response of the gas sensor slightly decreases from 181 to 175 after 4 days, and it

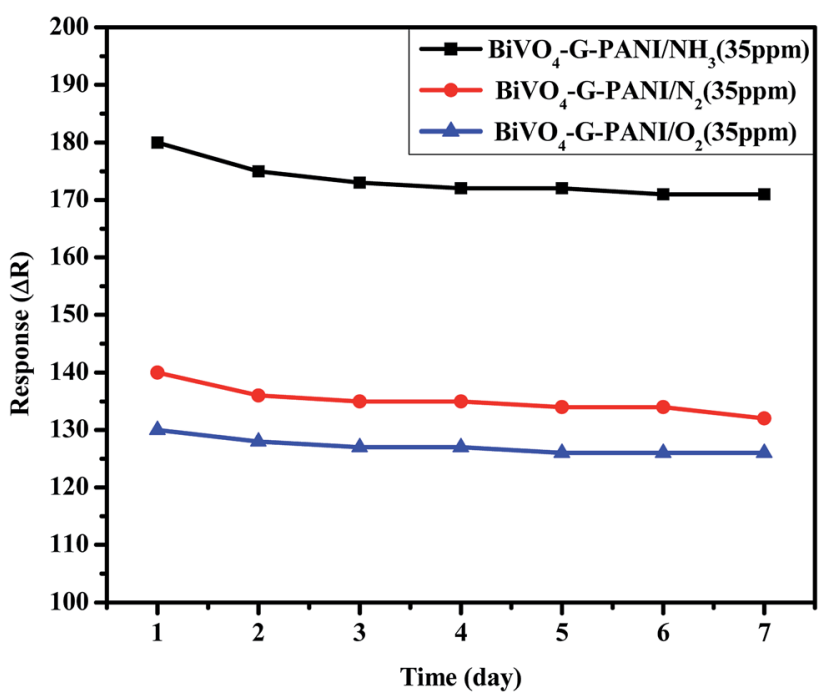

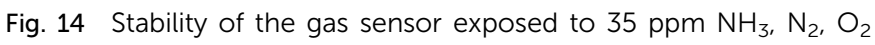
gases, with the $\mathrm{BiVO}_{4}-\mathrm{G}-\mathrm{PANI}$ sample. 


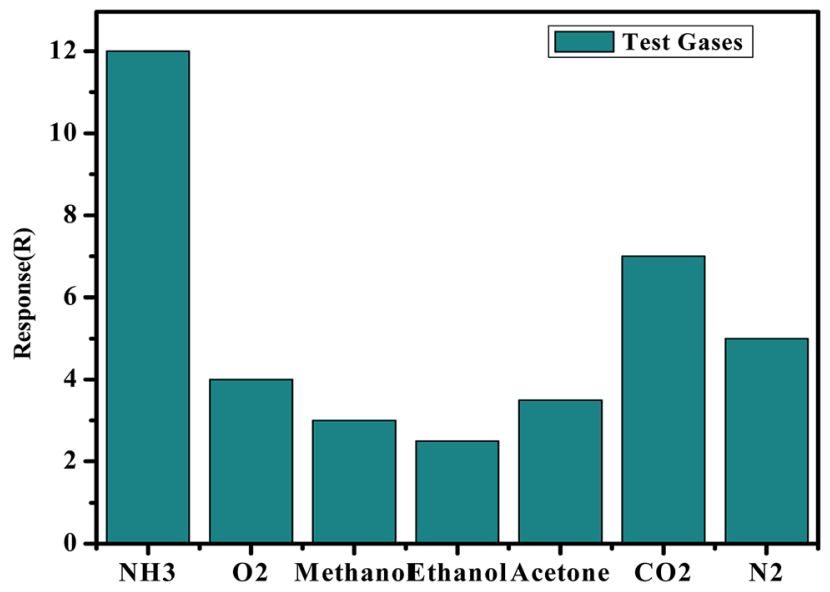

Fig. 15 Response of the sensor based on $\mathrm{BiVO}_{4}-\mathrm{GO}-\mathrm{PANI}$ to various gases at $25^{\circ} \mathrm{C}$.

remains almost unchanged for three days. Therefore, the stability of the sensor is quite good and enables long-term application.

\section{Selectivity}

More quantitatively, a comparison of sensitivity evolution with the nature of the gas (Fig. 15) shows that $\mathrm{NH}_{3}$ provides a response that is at least 2.5 times larger than the other gases (methanol, ethanol, acetone, $\mathrm{N}_{2}, \mathrm{CO}_{2}$ and $\mathrm{O}_{2}$ ) of nearly equivalent sensitivity. The reaction of poly-GO $(0.04 \mathrm{wt} \%)$ to the different gases can be ordered as follows from high to low response: $\mathrm{NH}_{3}>\mathrm{CO}_{2}>\mathrm{N}_{2}>\mathrm{O}_{2}>$ acetone $>$ methanol $>$ ethanol. The selectivity and response results demonstrate that the response of the sensor depends not only on the chemical interactions between analytes and PTFE, PVDF, PANI chains, but also on such parameters as adsorption of analytes on the graphene oxide, accessibility to adsorption sites, and swelling at junctions between graphene foils. ${ }^{45}$

\section{Conclusion}

In conclusion, a series of poly-GO/ $\mathrm{BiVO}_{4}$ heterojunction Schottky diodes were fabricated and their operation as roomtemperature ammonia, $\mathrm{N}_{2} \& \mathrm{O}_{2}$ gas sensors was investigated. The highest sensitivity of the sensor was demonstrated for the poly-GO composite with $0.04 \mathrm{wt} \%$ loading of GO sheets in the presence of PANI polymer. The ammonia sensors were shown to have high sensitivity and fast response time to different $\mathrm{NH}_{3}$ concentrations. Poly-GO-BiVO ${ }_{4}$ films could be used as an active sensing material in Schottky diode-type sensing applications that require high speed, high sensitivity, and outstanding selectivity.

\section{Conflicts of interest}

There are no conflicts to declare.

\section{References}

1 L. Aba, Y. Yusuf, D. Siswanta and K. Triyana, J. Nanotechnol., 2014, 2014, 864274.

2 H.-I. Chen, C.-Y. Hsiao, W.-C. Chen, C.-H. Chang, T.-C. Chou, I.-P. Liu, K.-W. Lin and W.-C. Liu, Sens. Actuators, B, 2018, 256, 962.

3 R. Ladhe, K. Gurav, S. Pawar, J. Kim and B. Sankapal, J. Alloys Compd., 2012, 515, 80.

4 T.-Y. Chen, H.-I. Chen, Y.-J. Liu, C.-C. Huang, C.-S. Hsu, C.-F. Chang and W.-C. Liu, Sens. Actuators, B, 2011, 155, 347.

5 S. Patil, P. Deshmukh and C. Lokhande, Sens. Actuators, B, 2011, 156, 450.

6 A. Salehi, A. Nikfarjam and D. J. Kalantari, IEEE Sens. J., 2006, 6, 1415.

7 A. Salehi, A. Nikfarjam and D. J. Kalantari, Sens. Actuators, B, 2006, 113, 419.

8 D. J. Late, Y. K. Huang, B. Liu, J. Acharya, S. N. Shirodkar, J. Luo, A. Yan, D. Charles, U. V. Waghmare, V. P. Dravid and C. N. R. Rao, Sensing behavior of atomically thinlayered $\mathrm{MoS}_{2}$ transistors, ACS Nano, 2013, 7(6), 4879-4891.

9 P. K. Kannan, D. J. Late, H. Morgan and C. S. Rout, Recent developments in 2D layered inorganic nanomaterials for sensing, Nanoscale, 2015, 7(32), 13293-13312.

10 D. J. Late, T. Doneux and M. Bougouma, Single-layer $\mathrm{MoSe}_{2}$ based $\mathrm{NH}_{3}$ gas sensor, Appl. Phys. Lett., 2014, 105(23), 233103.

11 M. B. Erande, M. S. Pawar and D. J. Late, Humidity sensing and photodetection behavior of electrochemically exfoliated atomically thin-layered black phosphorus nanosheets, ACS Appl. Mater. Interfaces, 2016, 8(18), 11548-11556.

12 D. J. Late, Liquid exfoliation of black phosphorus nanosheets and its application as humidity sensor, Microporous Mesoporous Mater., 2016, 225, 494-503.

13 A. S. Pawbake, R. G. Waykar, D. J. Late and S. R. Jadkar, Highly transparent wafer-scale synthesis of crystalline $\mathrm{WS}_{2}$ nanoparticle thin film for photodetector and humiditysensing applications, ACS Appl. Mater. Interfaces, 2016, 8(5), 3359-3365.

14 D. J. Late, R. V. Kanawade, P. K. Kannan and C. S. Rout, Atomically thin $\mathrm{WS}_{2}$ nanosheets based gas sensor, Sens. Lett., 2016, 14(12), 1249-1254.

15 J. N. Gavgani, A. Hasani, M. Nouri, M. Mahyari and A. Salehi, Sens. Actuators, B, 2016, 229, 239.

16 A. Hasani, H. S. Dehsari, J. N. Gavgani, E. K. Shalamzari, A. Salehi, F. A. Taromi and M. Mahyari, Microchim. Acta, 2015, 182, 1551.

17 C.-Y. Lin, J.-G. Chen, C.-W. Hu, J. J. Tunney and K.-C. Ho, Sens. Actuators, B, 2009, 140, 402.

18 M. Pawar, S. Kadam and D. J. Late, High-performance sensing behavior using electronic ink of 2D $\mathrm{SnSe}_{2}$ nanosheets, ChemistrySelect, 2017, 2(14), 4068-4075.

19 B. Chitara, D. J. Late, S. B. Krupanidhi and C. N. R. Rao, Room-temperature gas sensors based on gallium nitride nanoparticles, Solid State Commun., 2010, 150(41-42), 2053-2056. 
20 H. S. Dehsari, E. K. Shalamzari, J. N. Gavgani, F. A. Taromi and S. Ghanbary, RSC Adv., 2014, 4, 55067.

21 C. Y. Lee, Q. VanLe, C. Kim and S. Y. Kim, Phys. Chem. Chem. Phys., 2015, 17, 9369.

22 J. Liu, Y. Xue, Y. Gao, D. Yu, M. Durstock and L. Dai, Adv. Mater., 2012, 24, 2228.

23 Y. Sun, J. Tang, K. Zhang, J. Yuan, J. Li, D.-M. Zhu, K. Ozawa and L.-C. Qin, Nanoscale, 2017, 9, 2585.

24 M. S. A. S. Shah, S. Muhammad, J. H. Park, W.-S. Yoon and P. J. Yoo, RSC Adv., 2015, 5, 13964.

25 S. Ravula, C. Zhang, J. B. Essner, J. D. Robertson, J. Lin and G. A. Baker, ACS Appl. Mater. Interfaces, 2017, 9, 8065.

26 J. Xu, Z. Tan, W. Zeng, G. Chen, S. Wu, Y. Zhao, K. Ni, Z. Tao, M. Ikram and H. Ji, Adv. Mater., 2016, 28, 5222.

27 Y. R. Choi, Y.-G. Yoon, K. S. Choi, J. H. Kang, Y.-S. Shim, Y. H. Kim, H. J. Chang, J.-H. Lee, C. R. Park and S. Y. Kim, Carbon, 2015, 91, 178.

28 T. Wang, D. Huang, Z. Yang, S. Xu, G. He, X. Li, N. Hu, G. Yin, D. He and L. Zhang, Nano-Micro Lett., 2016, 8, 95.

29 D. Huang, X. Li, S. Wang, G. He, W. Jiang, J. Hu, Y. Wang, N. Hu, Y. Zhang and Z. Yang, Sens. Actuators, B, 2017, 252, 956.

30 R. Rella, P. Siciliano, F. Quaranta, T. Primo, L. Valli, L. Schenetti, A. Mucci and D. Iarossi, Sens. Actuators, B, 2000, 68, 203.

31 M. G. Manera, E. Ferreiro-Vila, A. Cebollada, J. M. GarcíaMartín, A. García-Martín, G. Giancane, L. Valli and R. Rella, J. Phys. Chem. C, 2012, 116, 10734.
32 R. Rella, J. Spadavecchia, G. Ciccarella, P. Siciliano, G. Vasapollo and L. Valli, Sens. Actuators, B, 2003, 89, 86.

33 M. C. Tanese, G. M. Farinola, B. Pignataro, L. Valli, L. Giotta, S. Conoci, P. Lang, D. Colangiuli, F. Babudri and F. Naso, Chem. Mater., 2006, 18, 778.

34 E. Comini, Anal. Chim. Acta, 2006, 568, 28.

35 J. N. Gavgani, H. S. Dehsari, A. Hasani, M. Mahyari, E. K. Shalamzari, A. Salehi and F. A. Taromi, RSC Adv., 2015, 5, 57559.

36 X. Wu, J. Liu, D. Wu, Y. Zhao, X. Shi, J. Wang, S. Huang and G. He, J. Phys. Chem. C, 2014, 2, 4044.

37 C. Wang, L. Yin, L. Zhang, D. Xiang and R. Gao, Sensors, 2010, 10, 2088.

38 G. F. Fine, L. M. Cavanagh, A. Afonja and R. Binions, Sensors, 2010, 10, 5469.

39 H. Bai and G. Shi, Sensors, 2007, 7, 267.

40 J. Reemts, J. Parisi and D. Schlettwein, Thin Solid Films, 2004, 466, 320.

41 J.-H. Cho, J.-B. Yu, J.-S. Kim, S.-O. Sohn, D.-D. Lee and J.-S. Huh, Sens. Actuators, B, 2005, 108, 389.

42 N. Kemp, A. Kaiser, H. Trodahl, B. Chapman, R. Buckley, A. Partridge and P. Foot, J. Polym. Sci., Part B: Polym. Phys., 2006, 44, 1331.

43 J. Jian, X. Guo, L. Lin, Q. Cai, J. Cheng and J. Li, Sens. Actuators, B, 2013, 178, 279. 